
ИСТОЧНИКОВ ПИТАНИЯ

\author{
А.Е. Лебединская ${ }^{1}$ Ю.А. Кабальнов ${ }^{1}$, А.Н. Труфанов ${ }^{1}$, А.В. Градобоев ${ }^{2}$ В.В. Седнев ${ }^{2}$ \\ ${ }^{1}$ Филиал РФЯЦ ВНИИЭФ «НИИИС им. Ю.Е. Седакова» \\ 603950, г. Нижний Новгород, БОКС №486; \\ 2 «Начиональный исследовательский Томский политехнический университет» \\ 634050, г. Томск, проспект Ленина, д. 30
}

Представлены результаты разработки оптоэлектронных пар для вторичных источников питания. Кристаллы источников оптического излучения созданы на основе двойных гетероэпитаксиальных структур арсенида галлия-алюминия, а кристаллы приёмников излучения структур - «кремний на сапфире». Сборка кристаллов в металлокерамические корпуса выполнена с применением оптически прозрачного кремнийорганического клея-герметика. Результаты испытаний оптоэлектронных пар показали уровень стойкости к $\gamma$-нейтронному излучению, соответствующий требованиям к радиаџионно стойкой аппаратуре систем управления и связи.

Ключевые слова: оптоэлектронная пара, источники и приёмники излучения, оптически прозрачная среда, структуры арсенида галлия-алюминия, структуры «кремний на сапфире», ионизирующее излучение, радиачионная стойкость

Сведения об авторах: Лебединская Анастасия Евгеньевна, Anastasia_le@mail.ru; Кабальнов Юрий Аркадьевич, к.т.н., Kabalnov@niiis.nnov.ru; Труфанов Алексей Николаевич, к.т.н., atrufanov@niiis.nnov.ru; Градобоев Александр Bасильевич, д.m.н., gradoboev1@mail.ru; Седнев Вячеслав Владимирович,vvs.05@mail.ru

\title{
RADIATION-RESISTANT OPTOCOUPLER FOR SECONDARY POWER SUPPLIES
}

A.E. Lebedinskaya ${ }^{1}$, Yu.A. Kabalnov ${ }^{1}$, A.N. Trufanov ${ }^{1}$, A.V. Gradoboev ${ }^{2}$, V.V. Sednev ${ }^{2}$

${ }^{1}$ Branch of the Federal State Unitary Enterprise «Russian Federal Nuclear Center - All-Russian Research Institute of Experimental Physics», «Yu.E. Sedakov Research Institute of Measuring Systems», 603950, Nizhniy Novgorod, box №486;

${ }^{2}$ National Research Tomsk Polytechnic University, 634050, Tomsk, Lenin Avenue, 30

In this paper we present the results of development of the optocouplers for secondary power supplies. The dies of the optical radiation emitters are based on double heteroepitaxial AlGaAs structures, and the dies of the radiation receivers are based on silicon-on-sapphire. Dies were bonded to metal-ceramic packages using the optically clear silicone-organic adhesive. The results of the optocoupler testing showed the level of resistance to $\gamma$-neutron radiation, which meets the requirements for radiationresistant devices used in control and communication systems.

Keywords: optocoupler, radiation emitters and receivers, optically clear medium, AlGaAs, silicon-onsapphire, ionizing radiation, radiation resistance

Data on authors: Lebedinskaya Anastasiya Evgenievna, anastasia_le@mail.ru; Kabalnov Yury Arkadievich,Ph.D., kabalnov@niiis.nnov.ru,TrufanovAlekseyNikolaevich,PיP.D., atrufanov@niiis.nnov.ru, Gradoboev Aleksandr Vasilyevich Sc.D., gradoboev1@mail.ru, Sednev Vyacheslav Vladimirovich, vvs.05@mail.ru. 


\section{Введение}

Перспективным направлением развития оптоэлектроники является разработка источников и приёмников излучения и оптоэлектронных изделий на их основе [1-4]. Для передачи информации между электрически не связанными устройствами могут эффективно использоваться оптроны и оптоэлектронные микросхемы. Наибольшее распространение получили оптроны с внешним электрическим входом и выходом и внутренней оптической связью. Оптоэлектронные устройства, содержащие в цепи сигнала оптические звенья, обеспечивают повышенную помехозащищённость каналов связи, устраняют паразитную связь по цепям земли и питания, обеспечивают возможность согласования цифровых устройств с различной элементной базой. Вместе с тем оптоэлектронным устройствам присущи недостатки, обусловленные низкой стойкостью элементов к воздействию ионизирующего излучения, что ограничивает их использование в радиационно стойкой аппаратуре систем управления и связи.

Оптоэлектронная пара функционально объединяет оптически связанные источник и приёмник излучения при условии электрической изоляции между входом и выходом. В оптоэлектронных парах чаще используются излучающие диоды на основе гетероэпитаксиальных структур соединений $\mathrm{A}_{3} \mathrm{~B}_{5}$ и кремниевые фотоприёмные устройства. Оптимальная длина волны излучения светодиодов и поглощения фотодиодов находится в ближнем инфракрасном спектральном диапазоне. Таким образом, в оптоэлектронных парах осуществляется принцип двойного преобразования энергии. При этом во входной цепи светодиод трансформирует электрические сигналы в оптическое излучение, которое преобразуется в фотодиодах в электрический ток в выходной цепи. Хотя диодные оптоэлектронные пары обеспечивают величину коэффициента передачи тока на уровне $1 \%$, на их основе могут быть созданы радиационно стойкие оптоэлектронные устройства, что отличает их от более чувствительных к радиации транзисторных оптоэлектронных пар.

В работе представлены результаты разработки оптоэлектронных пар с использованием радиационно стойких источников и приёмников излучения. Диодные оптоэлектронные пары создавались для применения во вторичных источниках питания с обеспечением гальванической развязки между управляющими цепями и исполнительными устройствами. Светодиоды были изготовлены на основе двойных гетероэпитаксиальных структур арсенида галлия-алюминия, а фотодиоды на основе гетероэпитаксиальных структур «кремний на сапфире» (КНС). Также описано конструктивное исполнение оптоэлектронных пар, собранных по схеме вертикального монтажа в металлокерамический корпус, и представлены результаты измерений основных электрических характеристик оптоэлектронных пар до и после воздействия $\gamma$-нейтронного излучения.

\section{Элементы структуры оптоэлектронных пар}

Требуемые уровни радиационной стойкости оптоэлектронных пар обеспечиваются стойкостью составляющих элементов. Основными элементами для диодных оптоэлектронных пар являются источник и приёмник оптического излучения, а также оптически прозрачная среда. Воздействие ионизирующего излучения приводит как 
к обратимым, так и к необратимым изменениям электрофизических и оптических параметров полупроводниковых материалов. Нейтроны высоких энергий смещают атомы кристаллической решётки, что приводит к генерации в структуре полупроводников вакансий и междоузельных атомов. Энергетические уровни дефектов в запрещённой зоне играют роль рекомбинационных центров и обусловливают сокращение времени жизни носителей заряда.

Соединения арсенид галлия-алюминия широко используются в качестве материала для создания светодиодов ИК спектрального диапазона. Достоинство этого материала заключается в возможности получения гетероэпитаксиальных структур с высоким качеством, с малым рассогласованием постоянных решётки при достаточно широком диапазоне изменения состава. Структурное совершенство позволяет получать предельный внутренний квантовый выход. В свою очередь, использование широкозонного окна позволяет на практике получить высокий внешний квантовый выход.

Образование дефектов при воздействии $\gamma$-нейтронного излучения приводит к снижению концентрации и подвижности неосновных носителей заряда, к изменению периода решётки слоёв гетероэпитаксиальных структур, но основным нежелательным радиационным эффектом является снижение светоотдачи светодиодов, обусловленное радиационным повреждением активного слоя гетероэпитаксиальной структуры. Снижение яркости светодиодов, обусловленное $\gamma$-нейтронным облучением, связано с образованием в активных слоях гетероэпитаксиальных структур центров безызлучательной рекомбинации.

При разработке кристаллов радиацион- но стойких светодиодов для оптоэлектронных пар за основу был принят полупроводниковый излучающий светодиод ИК диапазона длин волн, имеющий повышенную стойкость к воздействию ионизирующего излучения. Значения электрофизических параметров светодиода удовлетворяли требованиям по спектральным характеристикам, диаграмме направленности излучения, температурной зависимости мощности излучения. Длина волны излучения светодиода находится в ближней ИК области спектра. Конструктивное исполнение и габаритные размеры кристаллов светодиодов позволяли провести сборку в составе оптоэлектронной пары в металлокерамический корпус. Использовались структуры с гетероэпитаксиальными слоями арсенида галлия-алюминия $p^{+}-p-n-n^{+}$-типа проводимости. Радиационная стойкость светодиодов определяется толщиной активных слоёв гетероструктур и процентным содержанием компонент. Для повышения радиационной стойкости светодиодов пластины с гетероэпитаксиальными слоями утонялись до суммарной толщины $~ 150$ мкм. В качестве защитного покрытия использовали плёнки двуокиси кремния. Для формирования омических контактов к слоям $n$ - и $p$-типа проводимости после травления окон в защитном покрытии выполняли гальваническое осаждение металла. Основным элементом металлизации служило золото. После травления мезаструктур проводилась разбраковка кристаллов по электрофизическим параметрам. Схематично структура кристалла светодиода представлена на рис. 1.

При разработке конструкции и технологии изготовления кристаллов фотодиодов оптоэлектронных пар за прототип были приняты одно- и двухэлементные фотоди- 


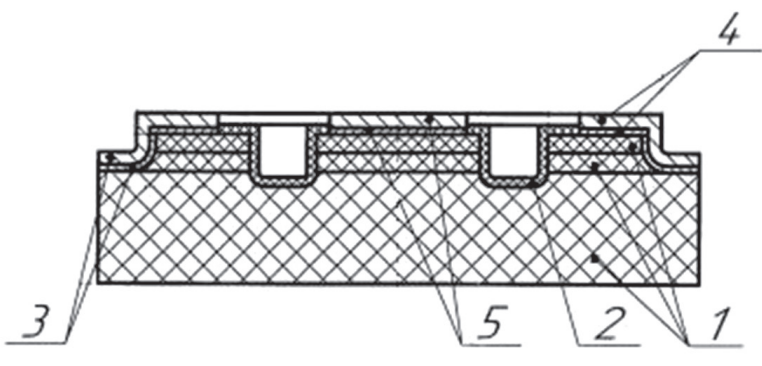

Puc. 1

Структура кристалла светодиода: 1 - эпитаксиальные слои; 2 - защитное покрытие; 3 - омический переход катодный; 4 - посадочная площадка; 5 - омический переход анодный

оды 2ОФ142А и 2ОФ143А [5]. Кристаллы фотодиодов серий 2ОФ142А и 2ОФ143А обладают высокой стойкостью к $\gamma$-нейтронному излучению и по основным параметрам соответствуют требованиям к электрофизическим характеристикам оптоэлектронных пар. Основой конструкции и технологии изготовления фотодиодов являются структуры «кремний на сапфире», что и определяет их стойкость к ионизирующему излучению. Толщина гетероэпитаксиальных плёнок кремния ( 5 мкм) КНС структур выбирается из расчёта величины области поглощения оптического излучения. Генерированные оптическим излучением носители заряда под действием электрического поля и диффузии заполняют слой кремния до границы раздела кремний-сапфир. В фотодиодах на кремниевых структурах носители заряда в зависимости от диффузионной длины диффундируют на глубину более 20 мкм. Наличие границы раздела в КНС структурах приводит к ограничению потоков носителей заряда в глубину структуры в отличие от диодов, изготовленных на кремниевых пластинах. Так как длина траектории движения электронов и дырок в КНС структурах меньше, чем в структурах на кремнии, вероятность захвата неосновных носителей заряда на радиационные дефекты вдоль траектории движения для КНС структур значительно меньше. За счёт снижения скорости захвата носителей радиационными дефектами повышается уровень радиационной стойкости КНС фотодиодов.

Расчёт параметров фотодиода выполняли с учётом соответствия требованиям к характеристикам оптоэлектронной пары. Учитывались требования по совместимости с источником оптического излучения и сборке в составе оптоэлектронной пары в металлокерамический корпус. Для оценки эффективности фоточувствительного приёмника рассматривались варианты топологии фотодиодов со сплошным анодом с ячеистой и полосковой структурой. Размер чувствительной площадки приёмника определяет уровень полезного сигнала, а также уровень помех и шумов. На чувствительность фотодиодов влияют такие факторы, как площадь фоточувствительных элементов, линейные размеры элементарных ячеек и расстояние между ними, принципы их размещения, диффузионная длина носителей заряда. Так как приборный слой в КНС структурах ограничен диэлектрической подложкой, сформировать фотодиоды со сплошным анодом и низкоомным заглубленным катодом достаточно сложно. При $\gamma$-нейтронном облучении большая площадь $p$ - $n$-перехода также способствует росту темнового тока, обусловленного радиационными дефектами. Токовая чувствительность фоточувствительных областей фотодиодов возрастает при формировании их в виде параллельного соединения элементарных диодов малой площади. Металлизация к областям анода и катода диодов выполняется как встречно-штыревая структура. На рис. 2 представлены 

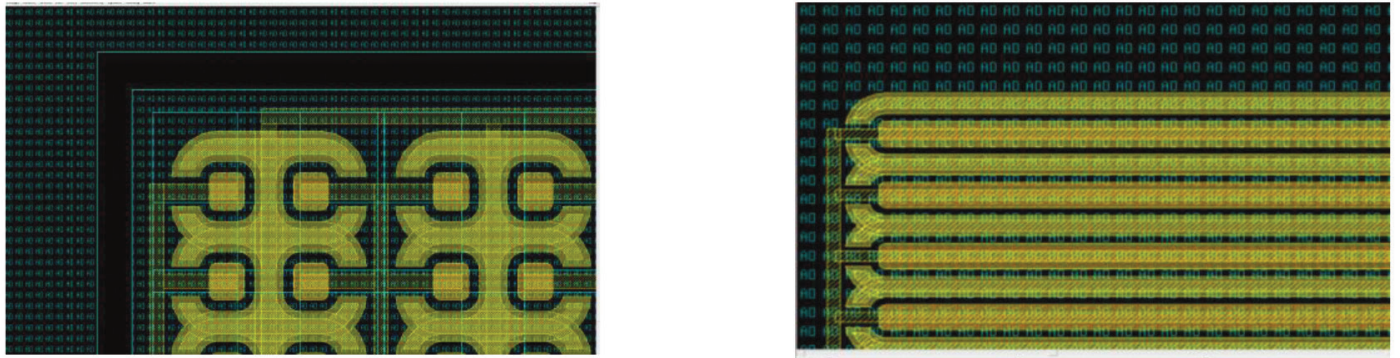

Puc. 2

Элементы топологии фотодиодов с ячеистой структурой и прямоугольным анодом

элементы топологии фотодиодов с ячеистой структурой и прямоугольным анодом. По критерию соотношения токовой чувствительности и темнового тока наибольшую эффективность показали фотодиоды с полосковыми прямоугольными анодами. Фотодиоды на КНС структурах реализуются по технологическому маршруту с использованием операций фотолитографии, осаждения диэлектрических и проводящих слоёв, операций ионного легирования, термических обработок и плазмохимического травления [5].

Коэффициент передачи тока оптоэлектронной пары можно повысить, уменьшив зазор между кристаллами излучателя и приёмника при оптимальном выборе оптической среды между ними. В качестве иммерсионной оптической среды оптоэлектронных пар был выбран оптически прозрачный кремнийорганический клей герметик «Эласил 137-180». Данный материал однокомпонентен, технологичен и при применении в качестве оптического контакта в детекторах остаётся прозрачным и устойчивым в диапазоне температур от минус 80 до плюс $200^{\circ} \mathrm{C}$. Для исследования радиационной стойкости клея-герметика были изготовлены специальные образцы размером 11х11х50 мм и проведены измерения оптических свойств образцов на спектрофотометре при длине волны излучения в диапазоне от 700 до 1100 нм до и после воздействия ионизирующего излучения. Внешний вид и масса образцов после испытаний не изменились. Изменения оптических характеристик образцов не превышали величину 10 \% в зависимости от воздействующего фактора.

\section{Конструкция оптоэлектронных пар}

Эффективность работы оптоэлектронных пар определяется характеристиками используемых кристаллов светодиодов и фотодиодов, а также типом корпуса и способом монтажа для достижения необходимого отвода тепла и минимальных внутренних напряжений в активной структуре. Требования радиационной стойкости обусловили сборку оптоэлектронных пар в металлокерамический корпус DIP (Dual-in-Line Package) с двухсторонним расположением выводов для монтажа в отверстия печатных плат. Корпус выполнен с применением высокотемпературной вакуумной керамики ВК-94-1. Использовалась так называемая вертикальная схема расположения кристаллов. Данный тип «вертикального» монтажа кристаллов наиболее эффективен для повышения коэффициента передачи тока между излучателем и приёмником, т.к. зазор между кристалла- 


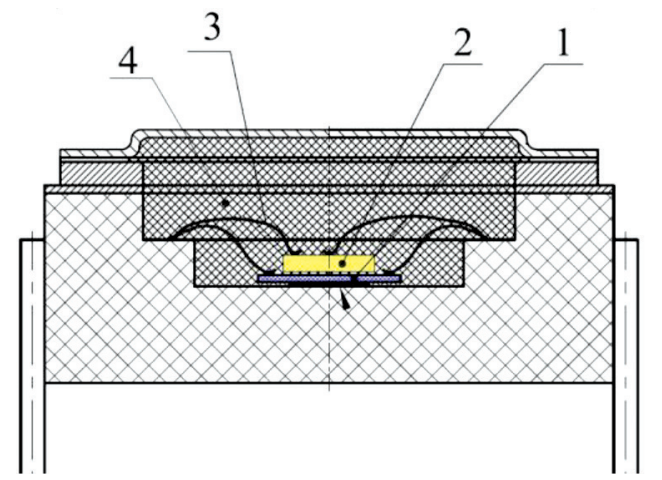

Puc. 3

Сборка оптоэлектронной пары в корпусе: 1 - кристалл фотодиода; 2 - кристалл светодиода; 3 - золотая проволока; 4 - компаунд «Эласил 137-180»

ми может быть снижен с использованием оптически прозрачного клея-герметика. На рис. 3 схематично показана оптоэлектронная пара, собранная в корпусе.

Кристаллы фотодиода монтировались в корпус с использованием клея. Затем алюминиевой проволокой разваривались выводы с контактных площадок корпуса на контактные площадки фотодиода. Выполнялась сварка золотых проволочных выводов на контактные площадки светодиода. Монтаж в корпус кристалла светодиода с разваренными выводами на кристалл фотодиода проводили с использованием оптического компаунда «Эласил 137-180». Выводы с контактных площадок светодиода разваривали на контактные площадки корпуса. Следует отметить, что разварку выводов на контактные площадки кристалла светодиода проводили до монтажа кристалла в сборку, т.к. оптический компаунд не обеспечивает достаточно жёсткого крепления для выполнения сварки. На рис. 4 представлен внешний вид оптоэлектронной пары в корпусе без крышки на этапе разварки выводов. Подкорпусной объём заливался оптическим компаундом с целью защиты кристаллов и внутренних

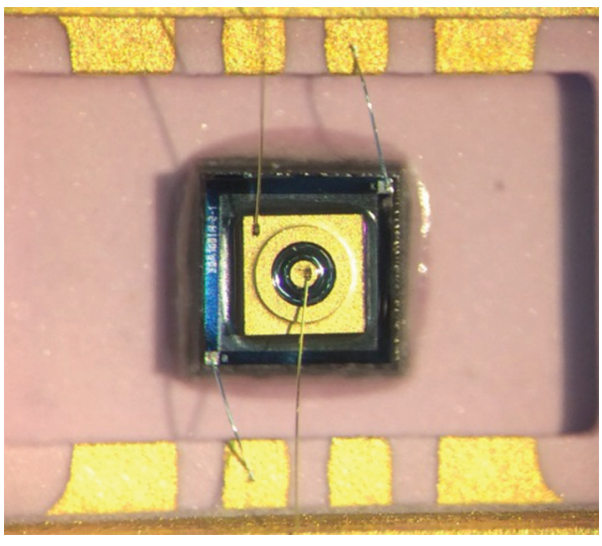

Puc. 4

Кристалль фотодиода и светодиода в корпусе без крышки

проволочных соединений от механических повреждений и воздействия окружающей среды. Для герметизации металлокерамических корпусов использовалась контактная шовная роликовая сварка.

\section{Результаты измерения параметров и их обсуждение}

Электрические параметры оптоэлектронных пар контролировалась на измерительном стенде с использованием контрольно-измерительного оборудования: тестера полупроводниковых приборов Formula-TT, источника питания и мультиметра (ф.Agilent). Измерительная оснастка включала блок коммутации и тестовые платы. Измерения параметров оптоэлектронных пар при крайних температурах проводились с использованием специально разработанного контактирующего устройства.

Контролировались следующие основные параметры оптопар: коэффициент передачи тока $K$, определяется как отношение тока на выходе к току на входе; постоянное прямое напряжение на излучателе $U_{\text {вx }}$; максимальный входной ток $I_{\text {вх }}$ при котором обеспечивается заданная надёжность при 
длительной работе прибора; ток, протекающий в выходной цепи диодной оптопары $I_{\text {вых}}$; активное сопротивление изоляции $R_{\text {из; }}$; максимальное напряжение изоляции, приложенное между входом и выходом оптопары, при котором сохраняется её электрическая прочность $U_{\text {из }}$; проходная ёмкость $C_{\text {из }}$ - ёмкость между входной и выходной цепью оптопары; граничная частота $f_{\text {гр }}$ частота, на которой модуль коэффициента передачи тока в режиме малого сигнала уменьшается по сравнению с его значением на низкой частоте с множителем $1 / \sqrt{ } 2$.

Величины измеренных параметров соответствовали свойственным диодным оптоэлектронным парам значениям. Средние значения коэффициента передачи тока $K$ равнялись $0.775 \%$ при постоянном прямом напряжении на излучателе $U_{\mathrm{Bx}}=1.26$ В и напряжении на приёмнике излучения $U_{\text {вых }}=5$ В. При этом средние значения входного тока светоизлучающих диодов составляли величину $I_{\text {вх }}=4.85$ мА, а средние значения тока в выходной цепи $I_{\text {вых }}=40.05$ мкА. Темновые токи фотодиодов не превышали величину 2.5 мкА. Измеренные значения активного сопротивления изоляции $R_{\text {из }}$ составляли $\sim 2 \cdot 10^{10} \mathrm{OM}$. Максимальное напряжение изоляции $U_{\text {из }}$, при котором сохранялась электрическая прочность оптопары, 1.5 кВ. Величина проходной ёмкости $C_{\text {из }}$ оптоэлектронных пар не превышала 5 пФ. Граничная частота $f_{\text {гр }}$ составляла величину $\sim 2$ мГц.

Величина коэффициента передачи тока определяется эффективностью источника и приёмника оптического излучения. Относительно низкие значения входных токов и напряжений исключали разогрев кристалла и снижение мощности излучения светодиодов. При сборке кристаллов в корпус выбор оптически прозрачного клея-герметика оказался эффективным для повышения коэффициента передачи тока между излучателем и приёмником за счёт снижения зазора между кристаллами. При этом обеспечивались требуемые значения активного сопротивления и максимального напряжения изоляции, при котором сохраняется электрическая прочность оптопары. Относительно низкие значения проходной ёмкости обусловливали работоспособность оптопар в мегагерцовом диапазоне частот.

Испытания на стойкость к механическим внешним воздействующим факторам подтвердили прочность конструкции оптоэлектронных пар. Работоспособность оптопар сохранялась при повышенных до $90^{\circ} \mathrm{C}$ температурах. Стойкость оптоэлектронных пар к воздействию ионизирующего излучения исследовалась на моделирующих установках, а также с использованием имитационного оборудования. Входной ток светодиодов $I_{\text {вх }}$ при наборе дозы излучения возрастал в среднем на $13 \%$, а выходной ток $I_{\text {вых }}$ с фотодиодов на $15 \%$. Наибольшие изменения параметров при дозовых нагрузках связаны с ростом величины темнового тока $I_{\text {т }}$ фотодиодов. Однако увеличение $I_{\mathrm{T}}$ не являлось критичным для функционирования оптоэлектронных пар. На рис. 5 представлен график зависимости величины темнового тока фотодиодов для трёх образцов оптопар от уровня $\gamma$-нейтронного излучения. Релаксация тока для образца № 2 определялась перерывом в наборе дозы при испытаниях и связана с восстановлением структуры диодов. Снижение коэффициента передачи тока $K$ при максимальных дозовых нагрузках составляло величину не более $5 \%$. По результатам проведения радиационных испытаний был подтверждён экстремальный уровень 


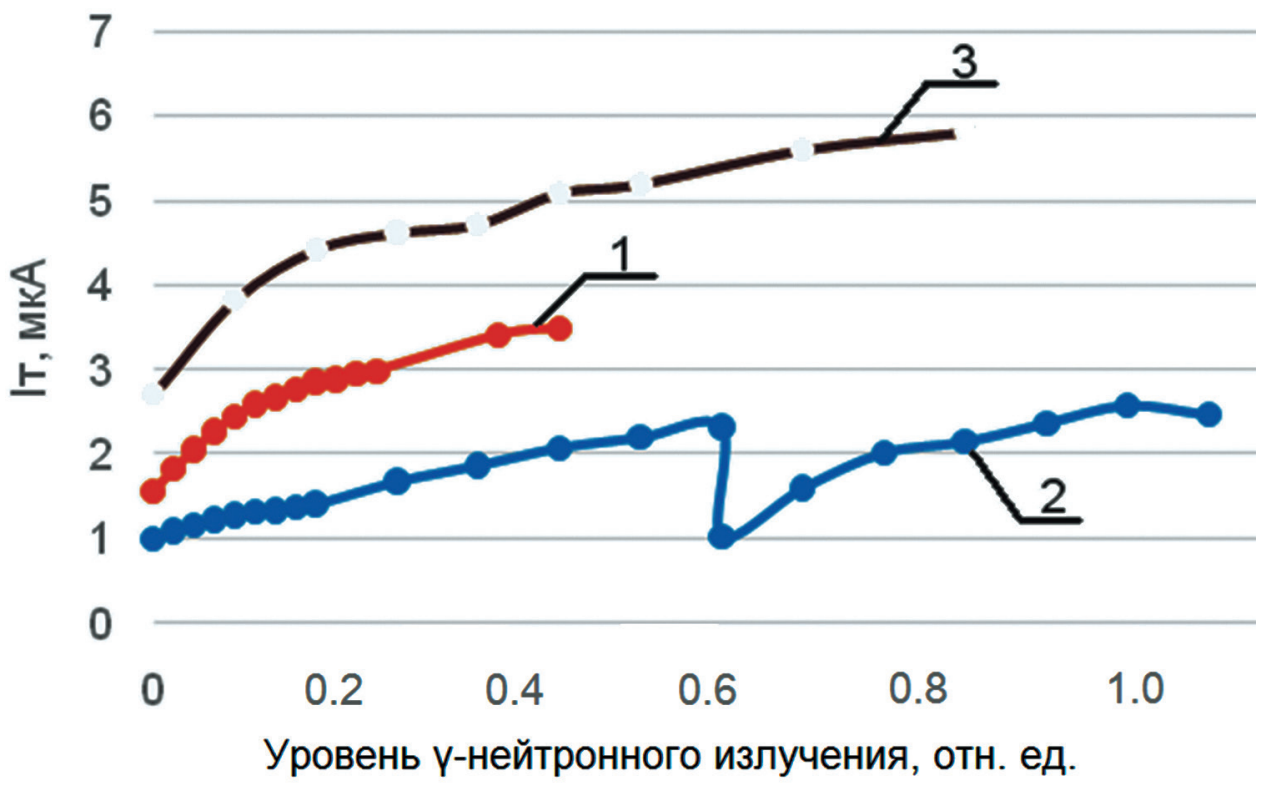

Puc. 5

График зависимости Iтот уровня $\gamma$-нейтронного излучения

стойкости оптоэлектронных пар к $\gamma$-нейтронному излучению.

Анализ полученных результатов свидетельствует, что электрические характеристики, а также стойкость к $\gamma$-нейтронному излучению определяются используемыми элементами структуры оптоэлектронных пар и их конструктивным исполнением. При проектировании конструкции и технологии изготовления оптоэлектронных пар успешно использовался накопленный ранее опыт разработки светодиодов и фотодиодов с повышенной стойкостью к $\gamma$-нейтронному излучению. Кристаллы светодиодов и фотодиодов были спроектированы с учётом совместимости по характеристикам и соответствия требованиям к параметрам оптопар. Учитывались также требования по сборке в корпус с применением схемы так называемого вертикального монтажа кристаллов. Испытания на стойкость к механическим и климатическим внешним воздействующим факторам подтвердили механическую прочность данной конструкции оптопар и их работоспособность при повышенных температурах.

\section{Заключение}

В работе представлены результаты разработки радиационно стойких оптоэлектронных пар, предназначенных для использования во вторичных источниках питания. В оптоэлектронных парах были функционально объединены источник и приёмник оптического излучения с повышенной стойкостью к $\gamma$-нейтронному излучению. Кристаллы светодиодов и фотодиодов проектировались с учётом требований совместимости их параметров. Оптимальная длина волны излучения светодиода и поглощения фотодиода находилась в ближней ИК области спектра и составляла $\sim 870$ нм. Светодиоды создавались с использованием гетероэпитаксиальных структур арсенида галлия-алюминия $p^{+}-p-n-n^{+}$-типа проводимости. Повышенная радиационная стойкость светодиодов 
обеспечивалась варьированием толщины активных слоёв гетероструктур и процентным содержанием компонент. В основу конструкции и технологии изготовления фотодиодов были заложены структуры «кремний на сапфире», что обусловливало их стойкость к $\gamma$-нейтронному излучению.

Для обеспечения требований стойкости к внешним воздействующим факторам сборку кристаллов светодиодов и фотодиодов выполняли в металлокерамические корпуса типа DIP. Монтаж кристалла светодиода на кристалл фотодиода проводили с использованием оптического компаунда, при этом грани выхода светового потока светодиодов совмещались через оптическую среду с гранями активной области поглощения фотодиодов. Уменьшение зазора между кристаллами излучателя и приёмника обусловливало повышение коэффициента передачи тока, при этом сохранялась величина активного сопротивления и максимального напряжения изоляции оптоэлектронных пар.

Параметры изготовленных структур соответствовали свойственным диодным оптоэлектронным парам значениям. По результатам проведения испытаний был подтверждён уровень стойкости к $\gamma$-нейтронному излучению, соответствующий требованиям к радиационно стойкой аппаратуре систем управления и связи. Измеренные значения электрофизических характеристик и достигнутые уровни радиационной стойкости обусловливают возможность применения оптоэлектронных пар в радиационно стойкой аппаратуре. На основе разработанной конструкции и технологии изготовления планируется организация их серийного производства под маркировкой 3ОД1001А.

\section{Литература}

1. Носов, Ю.Р. Оптроны и их применение / Ю.Р. Носов, Р.С. Сидоров. - М.: Радио и связь, 1981. $-279 \mathrm{c}$.

2. Носов, Ю.Р. Оптоэлектроника / Ю.Р. Носов. М.: Радио и связь, 1989. - 360 с.

3. Кайдалов, С.А. Фоточувствительные приборы и их применение / С.А. Кайдалов. - М.: Радио и связь, 1995. - 122 с.

4. Филачев, А.М. Твердотельная фотоэлектроника. Фотодиоды / А.М. Филачев, И.И. Таубкин, М.А. Тришенков. - М.: Физматкнига, 2011. $448 \mathrm{c}$.

5. Кабальнов, Ю.А. Особенности технологии радиационно стойких фотодиодов на структуpax «кремний на сапфире» / Ю.А. Кабальнов, А.Н. Труфанов, С.В. Оболенский // Электронная техника. Серия 2. Полупроводниковые приборы. - 2019. - Вып. 3 (254). - С. 38-47.

\section{References}

1. Nosov Yu.R., Sidorov R.S. Optrony i ikh primeneniye [Optocouplers and their application]. Moscow, Radio i svyaz', 1981, 279 p.

2. Nosov Yu.R., Optoelektronika [Optoelectronics], Moscow, Radio i svyaz', 1989, 360 p.

3. Kaydalov S.A., Fotochuvstvitel'nyye pribory i ikh primeneniye [Photosensitive devices and their application]. Moscow, Radio i svyaz’, 1995, 122 p.

4. Filachev A.M., Taubkin I.I., Trishenkov M.A. Tverdotel'naya fotoelektronika. Fotodiody [Solidstate photoelectronics. Photodiodes]. Moscow, Fizmatkniga, 2011, 448 p.

5. Kabalnov Yu.A., Trufanov A.N., Obolenskiy S.V. Osobennosti tekhnologii radiatsionno stoykikh fotodiodov na strukturakh kremniy na sapfire [Features of the technology of radiation-resistant photodiodes based on silicon-on-sapphire]. Electronic Engineering. Series 2. Semiconductor Devices, 2019, iss. 3 (254), pp. 38-47. 